\title{
Crescimento e Morfoanatomia Foliar de Eucalipto sob Efeito DE DeRiva do Glyphosate ${ }^{1}$
}

\author{
Leaf Growth and Morphoanatomy of Eucalypt under the Effect of Glyphosate Drift
}

\author{
TUFFI SANTOS, L.D. ${ }^{2}$, FERREIRA, F.A. ${ }^{3}$, MEIRA, R.M.S.A. ${ }^{3}$, BARROS, N.F. ${ }^{3}$, FERREIRA, L.R. ${ }^{3}$ e \\ MACHADO, A.F.L. ${ }^{4}$
}

\begin{abstract}
RESUMO - Os efeitos da deriva do glyphosate durante aplicação são prejudiciais à cultura do eucalipto. Neste trabalho, avaliou-se o efeito da deriva simulada do glyphosate no crescimento e na morfoanatomia foliar do eucalipto. Utilizou-se delineamento em blocos casualizados com quatro repetições, sendo a parcela experimental constituída de uma planta cultivada em vaso com 10 litros de solo. Os tratamentos foram $0 ; 43,2 ; 86,4 ; 172$,8; e 345,6 g e.a. ha ${ }^{-1}$ de glyphosate, aplicados aos 40 dias após o plantio das mudas com pulverizador de precisão, de modo a não atingir o terço superior das plantas. Foram descritas as alterações morfológicas na parte aérea e avaliada a porcentagem de intoxicação em relação à testemunha. Aos $7 \mathrm{e}$ 15 dias após aplicação (DAA), folhas coletadas no terceiro nó do primeiro ramo basal das plantas foram fixadas em $\mathrm{FAA}_{50}$ e estocadas em etanol $70 \%$. Cortes transversais da região mediana foram corados com azul de astra e fucsina básica e montados em lâminas permanentes. No laminário preparado foram mensuradas as espessuras do limbo, do parênquima paliçádico (PPA) e lacunoso (PLA), da epiderme das faces adaxial (EAD) e abaxial (EAB), bem como a proporção percentual da área de cada tecido, utilizando-se o software Image-Pro Plus. A partir de 5 DAA observou-se murcha, clorose e enrolamento das folhas nos ápices das plantas pulverizadas com 172,8 e $345,6 \mathrm{~g} \mathrm{ha}^{-1}$ de glyphosate. As plantas submetidas a 345,6 g e.a. ha-1 de glyphosate alcançaram $58,75 \%$ de toxidez aos 30 DAA, apresentando brotações anormais, o que não foi verificado nas concentrações menores. Aos 7 e 15 DAA, com 172,8 e 345,6 g e.a. ha-1 de glyphosate observaram-se áreas necrosadas e hiperplasia das células do parênquima clorofiliano e da epiderme. Em resposta à injúria, verificou-se a proliferação celular, formando tecido de cicatrização homogêneo, além de acúmulo de compostos fenólicos nas áreas afetadas. Aos 7 DAA verificou-se aumento na espessura do limbo e do PPA submetidos a 345,6 g e.a. ha ${ }^{-1}$ de glyphosate, enquanto o PLA e a EAD demonstraram acréscimo na espessura somente aos 15 DAA sob a mesma dosagem. As doses de 172,8 e 345,6 g e.a. ha-1 de glyphosate promoveram aumento na espessura do limbo e do PPA aos 15 DAA. O aumento na espessura do limbo é resultante da expansão das células do parênquima paliçádico, podendo estar relacionado à resposta das plantas à perda de área foliar específica, bem como à síntese de compostos secundários, como celulases, provocados pela ação do glyphosate.
\end{abstract}

Palavras-chave: Eucalyptus spp., anatomia, deriva simulada.

ABSTRACT - The effects of glyphosate drift during application are harmful to the eucalypt culture. This work evaluated the effects of simulated glyphosate drift on leaf growth and morphoanatomy of the clone 15-CENIBRA (Eucalyptus urophylla $X$ E. grandis). A randomized block design was used with four replications. Each experimental plot was represented by one plant cultivated in a 10 liter pot with soil. The treatments were 0; 43.2; 86.4; 172.8 and $34.6 \mathrm{~g}$ a.e. ha ${ }^{-1}$ of glyphosate, applied 40 days after seedling planting with a precision sprayer, so that the upper third of the plants was unaffected. The morphological alterations in the plant shoot were described .Intoxication percentage in relation to the control was evaluated 7,15 , and 30 days after application (DAA). Leaves were collected from the third node of the first basal branch of the plants, fixed in $F A A_{50}$ and stored in 70\% ethanol 7 and 15 DAA. Cross section of the intermediate region was stained with astra blue and basic fuchsia and installed on permanent slides to measure thickness, of the palisade

1 Recebido para publicação em 30.8.2004 e na forma revisada em 21.4.2005.

Parte da dissertação de mestrado do primeiro autor (Bolsista do CNPq).

2 Doutorando em Fitotecnia, Departamento de Fitotecnia da Universidade Federal de Viçosa - UFV, 36570-000 Viçosa-MG, $<$ ltuffi@yahoo.com.br $>;{ }^{3}$ Professor do Dep. de Fitotecnia - UFV; ${ }^{4}$ Mestrando em Fitotecnia - UFV. 
(PPA) and spongy (PLA) parenchyma, epidermis of the adaxial (EAD) and abaxial (EAB) sides, as well as the proportion of each tissue area using software "Image-Pro Plus". From the 5th DAA, leaf wilt, chlorosis and curling were observed in the plant apices sprayed with 17.8 and $345.6 \mathrm{~g}$ a.e. ha of $^{-1}$ glyphosate. The plants subjected to $24 \%$ of the rate attained $58.75 \%$ toxicity 30 DAA, presenting abnormal branch, which was not observed under lower concentrations. Twelve and $345.6 \mathrm{~g}$ i.a. $\mathrm{ha}^{-1}$ of glyphosate caused necrotic area, hyperplasia of the chlorophyllic parenchyma and epidermis cells, 7 and 15 DAA. In response to the injuries, cell proliferation forming a homogeneous scar tissue and accumulation of phenolic compounds in the affected areas was verified. Blade thickness and PPA subjected to $345.6 \mathrm{~g}$ a.e. ha $\mathrm{h}^{-1}$ of glyphosate increased 7 DAA, while PLA and EAD showed increased thickness only 15 DAA at the same rate. The sub doses of 172.8 and $345.6 \mathrm{~g}$ a.e. $\mathrm{ha}^{-1}$ of glyphosate led to an increase in blade thickness and PPA 15 DAA. The increase in blade thickness is a result of expansion of the palisade parenchyma cell, which may be related to a specific response of the plants to leaf area loss, as well as to synthesis of secondary compounds such as cellulases, due to glyphosate action.

Key words: Eucalyptus spp., anatomy, simulated drift.

\section{INTRODUÇÃO}

O eucalipto é a essência florestal mais usada nos programas de reflorestamento no Brasil, em razão de suas características de rápido crescimento e boa adaptação às condições edafoclimáticas existentes no país. Segundo a Sociedade Brasileira de Silvicultura (2004), o eucalipto é responsável por gerar mais de dois milhões de empregos diretos e indiretos e contribuir com aproximadamente $4 \%$ do PIB nacional.

Apesar de o gênero Eucalyptus apresentar espécies de rápido crescimento e de boa competitividade quanto a seu estabelecimento no campo, isso não o isenta da interferência das plantas daninhas, tendo como conseqüência o decréscimo quantitativo e qualitativo da sua produção. Esse fato coloca as plantas daninhas como um grande problema para implantação e manutenção de florestas de eucalipto, o que tem fomentado o interesse de vários pesquisadores nas últimas décadas.

O manejo das plantas daninhas em reflorestamentos é baseado praticamente em métodos químicos e mecânicos, isolados ou combinados (Toledo et al., 2003). No caso das empresas florestais, que geralmente cultivam extensas áreas, não só a escassez de mão-de-obra, mas a necessidade de atingir elevados índices de produtividade, dentro de padrões econômicos aceitáveis, tem levado ao aumento do uso da capina química como alternativa para redução dos custos de produção
(Ribeiro, 1988). O uso de herbicidas como ferramenta para o manejo de plantas daninhas deve ser sempre aliado à preocupação com o risco de ocorrência de danos a organismos não-alvos e à saúde humana. Logo, na escolha do produto devem-se levar em conta os beneficios do seu uso, os fatores econômicos, a forma de aplicação e o possível risco da deriva (Gelmini, 1988).

O glyphosate é o herbicida mais usado no controle de plantas daninhas na cultura do eucalipto. Seu uso tem se destacado nos cultivos comerciais, por exercer efetivo controle de grande número de espécies daninhas, sem ser ambientalmente agressivo (Malik et al., 1989). Herbicidas à base de glyphosate têm sido usados tanto no preparo da área quanto no plantio, no replantio e na manutenção de reflorestamentos de eucalipto.

Apesar das várias características favoráveis do glyphosate, entre elas a pressão de vapor praticamente nula do sal de isopropilamina (Ahrens, 1994), o maior problema do uso deste herbicida em eucalipto é a deriva acidental. A ocorrência de deriva compromete o controle das plantas daninhas e leva ao aumento compensatório da dosagem, elevando os gastos e causando prejuízos às espécies não-alvo e ao meio ambiente (Hemphill Júnior e Montgomery, 1981). Em reflorestamentos de eucalipto são comuns aplicações dirigidas com glyphosate, visando o controle de plantas daninhas nas entrelinhas de cultivo. Também, em talhões destinados à implantação ou reforma do eucaliptal é freqüente o uso da 
dessecação com glyphosate por meio de aeronaves. Sob condições climáticas ideais para aplicação, a deposição de produtos devido à deriva gira em torno de 5 e $9 \%$ da dose aplicada com equipamentos terrestres (Bode, 1984). Esse risco é maior em pulverizações aéreas, que produzem faixas de pulverização pouco precisas, em razão do menor volume de calda aplicada e da maior altura em relação ao alvo (Yates et al., 1978).

O efeito da deriva de formulações herbicidas está diretamente ligado à quantidade do principio ativo que chega às culturas, que por sua vez está diretamente associado às doses recomendadas para controle das plantas daninhas. Segundo Rodrigues \& Almeida (1998), as doses recomendadas do glyphosate para o eucalipto variam muito, sendo usados de 360 a 2.160 g e.a. ha-1 para o controle de espécies anuais e perenes.

Mudas ou brotações de plantas de eucalipto, em áreas onde o glyphosate tem sido usado no controle de plantas daninhas, têm apresentado sintomas de intoxicação na parte aérea. A iminente possibilidade da ocorrência de injúrias devido à deposição de herbicidas provindos da deriva tem levado a várias pesquisas envolvendo o conceito de "deriva simulada". Quanto à determinação dos tratamentos a serem utilizados em estudos de deriva simulada, há uma grande variação nas subdoses adotadas pelos autores para os diversos herbicidas e culturas. Os efeitos de doses letais de herbicidas sobre as folhas das plantas são conhecidos, sendo o contrário observado sobre os efeitos da exposição a doses não-letais, devido à deriva (Hemphill Júnior \& Montgomery, 1981). Apesar da importância do glyphosate para cultura do eucalipto, na literatura não existem trabalhos que visem elucidar os efeitos diretos e indiretos da molécula do herbicida nesta espécie florestal.

Diante do exposto, o presente trabalho teve como objetivo estudar o efeito da deriva simulada de glyphosate, por meio de subdoses, no crescimento e na morfoanatomia foliar de plantas do clone 15-CENIBRA híbrido Eucalyptus urophylla $\mathrm{x}$ E. grandis.

\section{MATERIAL E MÉTODOS}

O experimento foi realizado em casa de vegetação pertencente ao Departamento de
Fitotecnia da Universidade Federal de Viçosa, entre os meses de outubro de 2003 e janeiro de 2004, com temperaturas médias máximas e mínimas de 26,63 e $14,73{ }^{\circ} \mathrm{C}$, respectivamente.

Mudas padronizadas do clone 15- CENIBRA, híbrido Eucalyptus urophylla $\mathrm{x}$ E. grandis, com aproximadamente $30 \mathrm{~cm}$ de altura e 3 meses de idade, foram plantadas em vasos com $10 \mathrm{~L}$ de solo argiloso, adubados com 216,6 g de N-P-K (6-30-6) e 12 g de calcário, cuja proporção Ca/ $\mathrm{Mg}$ era de 4:1 equivalentes. A adubação de cobertura foi feita com $12 \mathrm{~g} /$ vaso de N-P-K (20-5-20), parcelados em duas vezes, com irrigação por microaspersão. Utilizou-se o delineamento em blocos casualizados, com quatro repetições, sendo cada vaso considerado uma parcela experimental.

Os tratamentos consistiram das subdoses de $0 ; 43,2 ; 86,4 ; 172,8$; e 345,6 g e.a. ha-1 de glyphosate, correspondentes, respectivamente, a $0,3,6,12$ e $24 \%$ da dose de 1.440 g e.a. ha ${ }^{-1}$ da formulação sal de isopropilamina. Os tratamentos foram aplicados 40 dias após o plantio das mudas, quando as plantas de eucalipto apresentavam cerca de $60 \mathrm{~cm}$ de altura, de modo que não atingisse o terço superior das plantas (Figura 1). Na aplicação, usou-se pulverizador costal de precisão, munido de barra com dois bicos com pontas tipo leque TT110.02

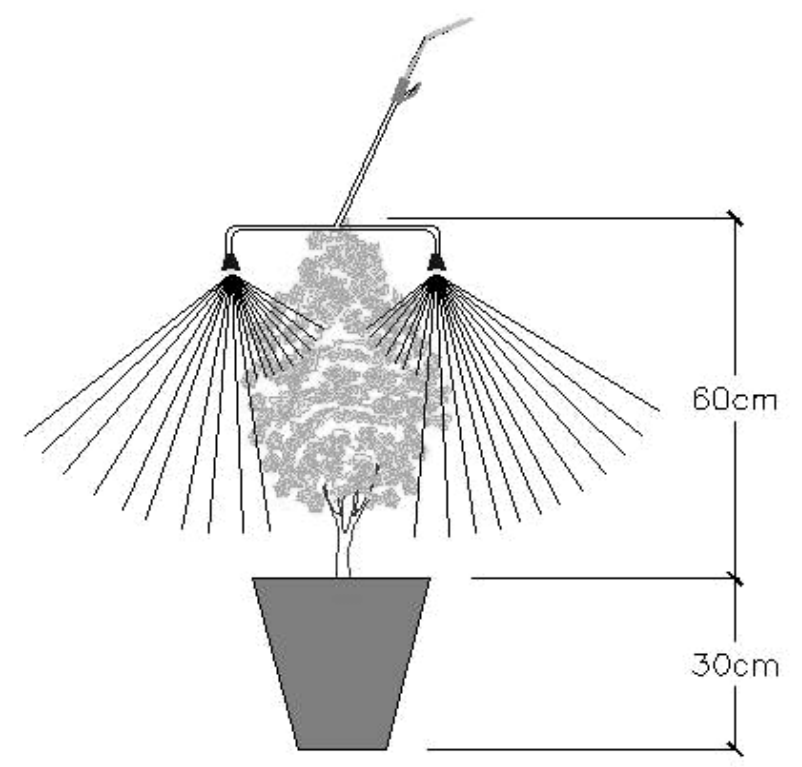

Figura 1 - Esquema da pulverização do glyphosate simulando a deriva nas plantas de eucalipto, de forma a não atingir o terço superior das plantas.

Planta Daninha, Viçosa-MG, v. 23, n. 1, p. 133-142, 2005 
espaçadas de $0,5 \mathrm{~m}$, operando a $250 \mathrm{kPa}$ de pressão, trabalhando com volume de calda correspondente a $200 \mathrm{~L} \mathrm{ha}^{-1}$. No momento da aplicação dos tratamentos a umidade relativa do ar encontrava-se a $80 \%$, a temperatura, a $25{ }^{\circ} \mathrm{C}$ e com ausência de ventos

Depois da aplicação do herbicida foram observadas, periodicamente, alterações morfológicas na parte aérea das plantas visiveis a vista desarmada. Aos 7, 15 e 30 dias após à aplicação (DAA) determinou-se a porcentagem de intoxicação em relação à testemunha, em que $0 \%$ corresponde à ausência de sintomas visíveis e $100 \%$ à morte das plantas (Frans, 1972).

Aos 7 e 15 DAA foram coletadas folhas do terceiro nó do primeiro ramo basal das plantas de eucalipto. O material coletado foi fixado em FAA $_{50}$ por 24 horas, dentro de frascos colocados em dessecador submetido a vácuo e posteriormente estocado em etanol 70\% (Johansen, 1940). Do material estocado retiraram-se amostras da porção mediana das folhas, que foram incluídas e emblocadas em parafina, usando-se álcool butílico terciário para a desidratação (Johansen, 1940). Dos blocos foram obtidos, em micrótomo rotativo de avanço automático (LEICA RM2155), cortes transversais com $12 \mu \mathrm{m}$ de espessura, que posteriormente foram corados com azul de astra e fucsina básica (Gerlach, 1984) para montagem em lâminas com bálsamo-do-canadá. Para observação da epiderme, amostras das folhas foram diafanizadas com hipoclorito de sódio (Sass, 1951) e coradas com fucsina básica.

No laminário histológico preparado, foram observados os efeitos do glyphosate sobre a estrutura anatômica da folha. Nos cortes transversais foram mensuradas as espessuras do limbo, do parênquima paliçádico (PPA), do parênquima lacunoso (PLA) e da epiderme das faces adaxial (EAD) e abaxial (EAB), assim como a área dos referidos tecidos, em porcentagem da área total da seção transversal da folha. Os dados de espessura e área foram obtidos com auxílio do software Image-Pro Plus, perfazendo um total de 27 e 9 observações/ repetição para espessura e área, respectivamente, para cada estrutura avaliada. As observações e ilustrações foram obtidas em fotomicroscópio (Olympus AX 70) com sistema $\mathrm{U}$ - Photo.
Aos 50 DAA, obtiveram-se dados sobre a altura das plantas (região entre o coleto e o ápice das plantas) e o diâmetro do caule a $1 \mathrm{~cm}$ do solo. A parte aérea das plantas foi colhida e acondicionada em sacos de papel mantidos em estufa com circulação de ar $\left(65 \pm 3^{\circ} \mathrm{C}\right)$ até atingir peso constante, para obtenção da matéria seca.

Os dados quantitativos foram submetidos à análise de variância e as médias comparadas a $5 \%$ de probabilidade pelo teste de Tukey; os dados referentes à porcentagem de intoxicação foram transformados em arco seno $\sqrt{(\mathrm{x}+0,05) / 100}$, sendo ajustadas equações de regressão.

\section{RESULTADOS E DISCUSSÃO}

A partir do quinto dia após aplicação do glyphosate (DAA), observaram-se murcha, clorose e enrolamento das folhas dos ápices das plantas pulverizadas nas doses de 172,8 e 345, 6 g e.a. ha-1 (Figura 2A e C), e os mesmos sintomas, em menor intensidade, para 86,4 g e.a. ha-1 de glyphosate. Tuffi Santos et al. (2004) relatam sintomas foliares semelhantes em espécies de plantas daninhas do gênero Commelina. A mudança na coloração da folha pode estar relacionada à degeneração dos cloroplastos, verificada por Campbell et al. (1976) em plantas tratadas com glyphosate, ou aos efeitos do herbicida sobre a inibição da formação de clorofila, descrita por Cole et al. (1983).

As porcentagens de intoxicação variaram entre as diferentes doses testadas $(\mathrm{p}<0,01)$ aos 7,15 e 30 DAA. A intoxicação nas plantas foi maior com o aumento das subdoses de glyphosate, sendo ajustadas curvas sigmóides com alto ajuste aos dados para as três épocas de avaliação (Figura 3).

Aos 15 DAA, as plantas de eucalipto que receberam a dose de 345,6 g e.a. ha ${ }^{-1}$ de glyphosate apresentavam folhas coriáceas, deformadas, necroses bem desenvolvidas nos bordos das folhas e pontos necróticos pelo limbo foliar, que podem ser confundidos com sintomas semelhantes aos observados em plantas tratadas com herbicidas de contato (Figura 2D a F). As doses de 172,8 e 345,6 $\mathrm{g} \mathrm{ha}^{-1}$ de glyphosate provocaram a morte dos ápices 
das plantas aos $15 \mathrm{DAA}$, alcançando, respectivamente, 16,5 e $58,75 \%$ de intoxicação aos 30 DAA (Figura 3). Entretanto, apenas as plantas tratadas com a maior dose apresentaram brotações anormais, senescência foliar acentuada e sintomas semelhantes aos da deficiência por nutrientes. Dantas et al. (2001), trabalhando com glyphosate no controle da rebrota de cepas em diferentes clones de eucalipto, relatam o surgimento de brotações com sintomas de intoxicação e também o efeito do herbicida na parte aérea das plantas tratadas. Segundo o autor, as plantas de eucalipto apresentavam folhas amarronzadas aos 14 DAA, semelhante ao impacto causado pelo calor do fogo, que deixa as folhas com aspecto de "sapecadas".

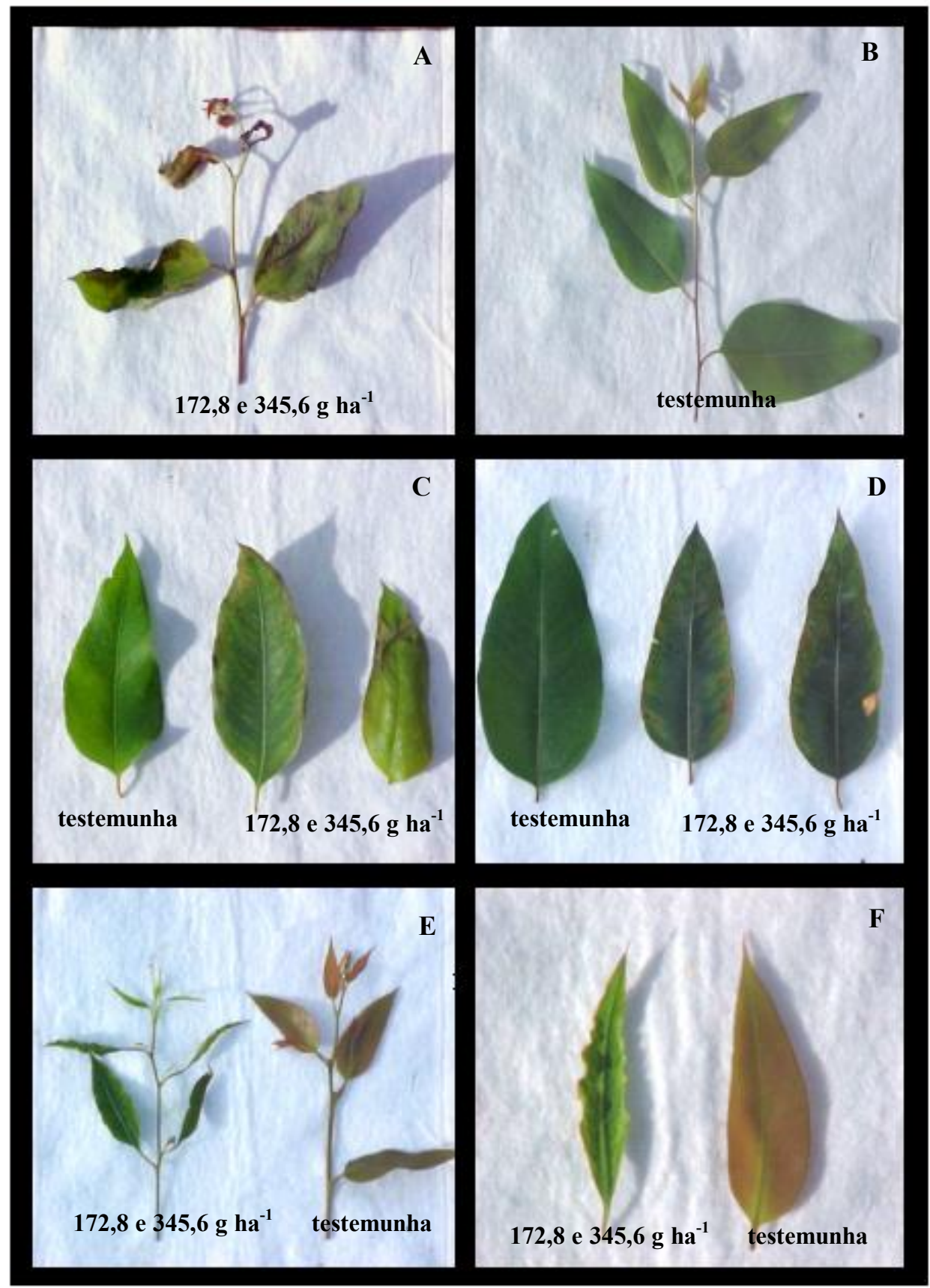

Figura 2 - Aspecto de folhas e ramos de plantas de eucalipto submetidas à deriva simulada de glyphosate aos 7 dias após aplicação (DAA) do herbicida, em A, B e C, e aos 15 DAA, em D, E e F. 

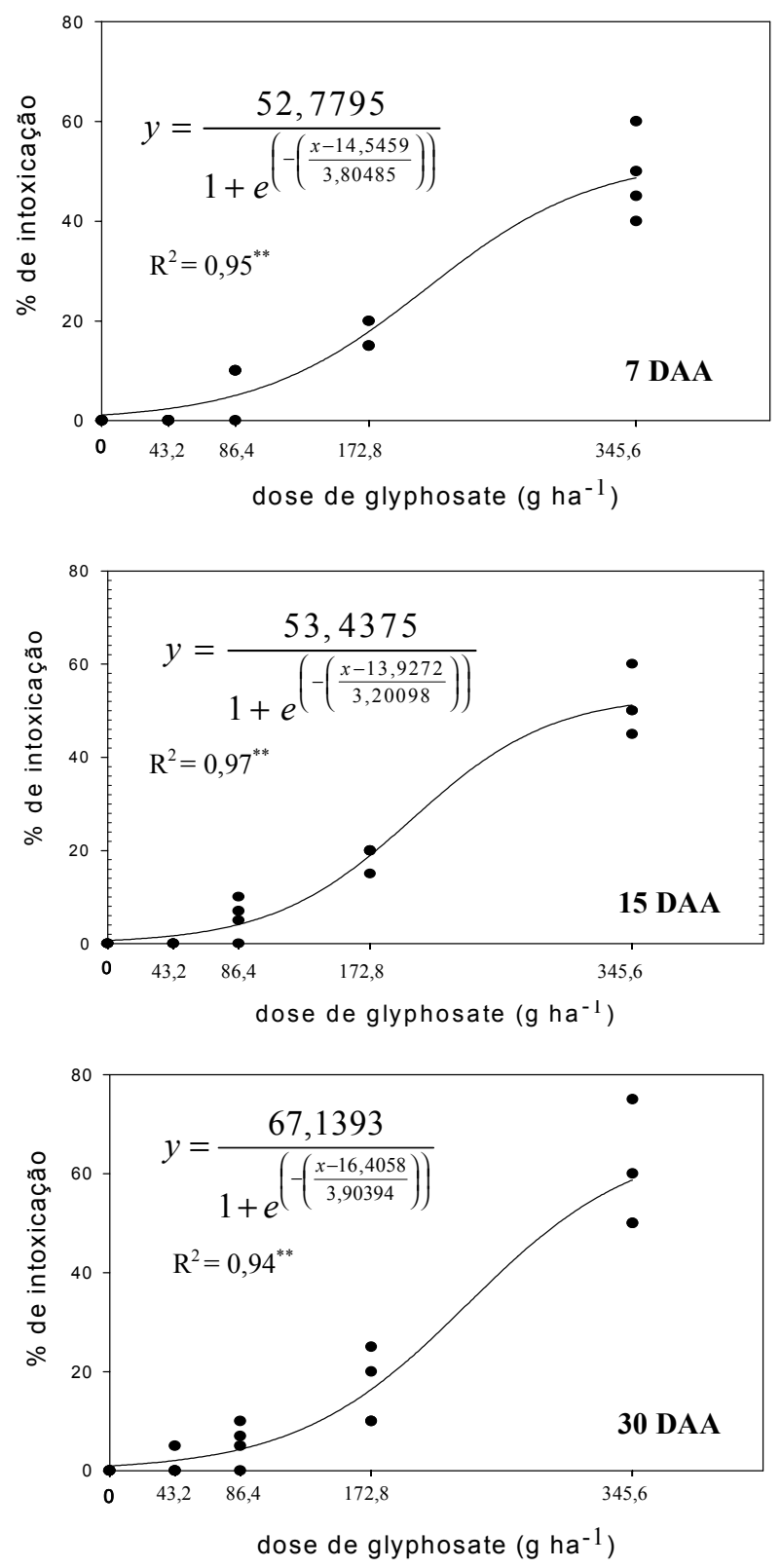

Figura 3 - Porcentagem de intoxicação de plantas de eucalipto submetidas às doses de $0 ; 43,2 ; 86,4 ; 172,8$; e 345,6 g e.a. ha $^{-1}$ de glyphosate, aos 7, 15 e 30 dias após aplicação (DAA).

Magalhães et al. (2001a), trabalhando com simulação de deriva do glyphosate na cultura de milho, afirmam que os prejuízos são diretamente proporcionais ao aumento das doses do herbicida. A partir de 115,29 g e.a. ha ${ }^{-1}$ de glyphosate, as plantas tratadas apresentaram necroses na parte aérea e comprometimento na produtividade, chegando a $53 \%$ de intoxicação com 172,8 g e.a. ha-1 de glyphosate.
Dados semelhantes foram obtidos para a cultura do sorgo sob as mesmas condições experimentais (Magalhães et al., 2001b).

As médias referentes a altura, diâmetro e matéria seca das plantas e seus respectivos testes de médias encontram-se na Tabela 1. A altura e matéria seca das plantas variaram entre as diferentes subdoses testadas $(p<0,01)$, o que não foi verificado no diâmetro dos caules $(p>0,05)$.

Plantas submetidas a 345,6 g e.a. ha ${ }^{-1}$ de glyphosate apresentaram menor altura e matéria seca, enquanto as demais doses não diferiram entre si para os referidos parâmetros. Não houve diferença entre os tratamentos para o diâmetro dos caules (Tabela 1). A morte do ápice das plantas tratadas com a maior dose de glyphosate, juntamente com injúrias severas, presença de brotações nãoviáveis (anormais) e senescência das folhas, explica a menor altura e matéria seca observadas nas plantas. Entretanto, plantas submetidas a 172,8 g e.a. ha ${ }^{-1}$ obtiveram maior altura, apesar de não diferirem estatisticamente das plantas tratadas com as doses menores. Esta dose também provocou a morte do ápice das plantas aos 15 DAA; contudo, suas injúrias foram menos expressivas, não levando à senescência foliar e possibilitando a formação de brotações normais, que assumiram a dominância apical das plantas, retomando seu crescimento normal.

No laminário histológico foram observadas regiões necrosadas com 172,8 e 345,6 g e.a. ha-1 de glyphosate aos 7 e 15 DAA. Nessas áreas observou-se hiperplasia das células do parênquima clorofiliano e epiderme, levando ao colapso desses tecidos (Figura 4E e F). Em resposta à injúria, verificou-se proliferação celular, formando tecido de cicatrização homogêneo, isolando as áreas necrosadas dos tecidos não afetados. Também foi constatada maior intensidade de células coradas pela fucsina básica, provavelmente devido ao acúmulo de compostos fenólicos, comuns no gênero Eucalyptus (Figura 4C, D, E e F). Entretanto, testes histoquímicos devem ser realizados para confirmação da natureza desses conteúdos. Nas plantas tratadas com subdoses acima de 86,4 g e.a. ha ${ }^{-1}$ de glyphosate podem-se observar, com freqüência, tanto nos cortes transversais (Figura 4B) como 
no material diafanizado (Figura 5B a E), células da face adaxial da epiderme mortas pela ação do herbicida.

Segundo Rizzardi et al. (2003), o glyphosate pode interferir nas reações das plantas ao ataque de patógenos. Para Lévesque $\&$ Rahe (1992), subdoses de glyphosate podem causar redução do acúmulo tanto de fitoalexinas quanto de lignina, as quais são consideradas barreiras físico-fisiológicas da planta, levando a uma maior severidade das doenças. Nesse sentido, a presença de células mortas na epiderme pode constituir uma via facilitadora da entrada de patógenos em plantas expostas à deriva, o que enfatiza os problemas da deriva do glyphosate como fator agravante no controle de doenças em eucalipto.

O estímulo da divisão celular de diferentes tecidos foliares em eucalipto foi visualizado nos cortes transversais de folhas pulverizadas
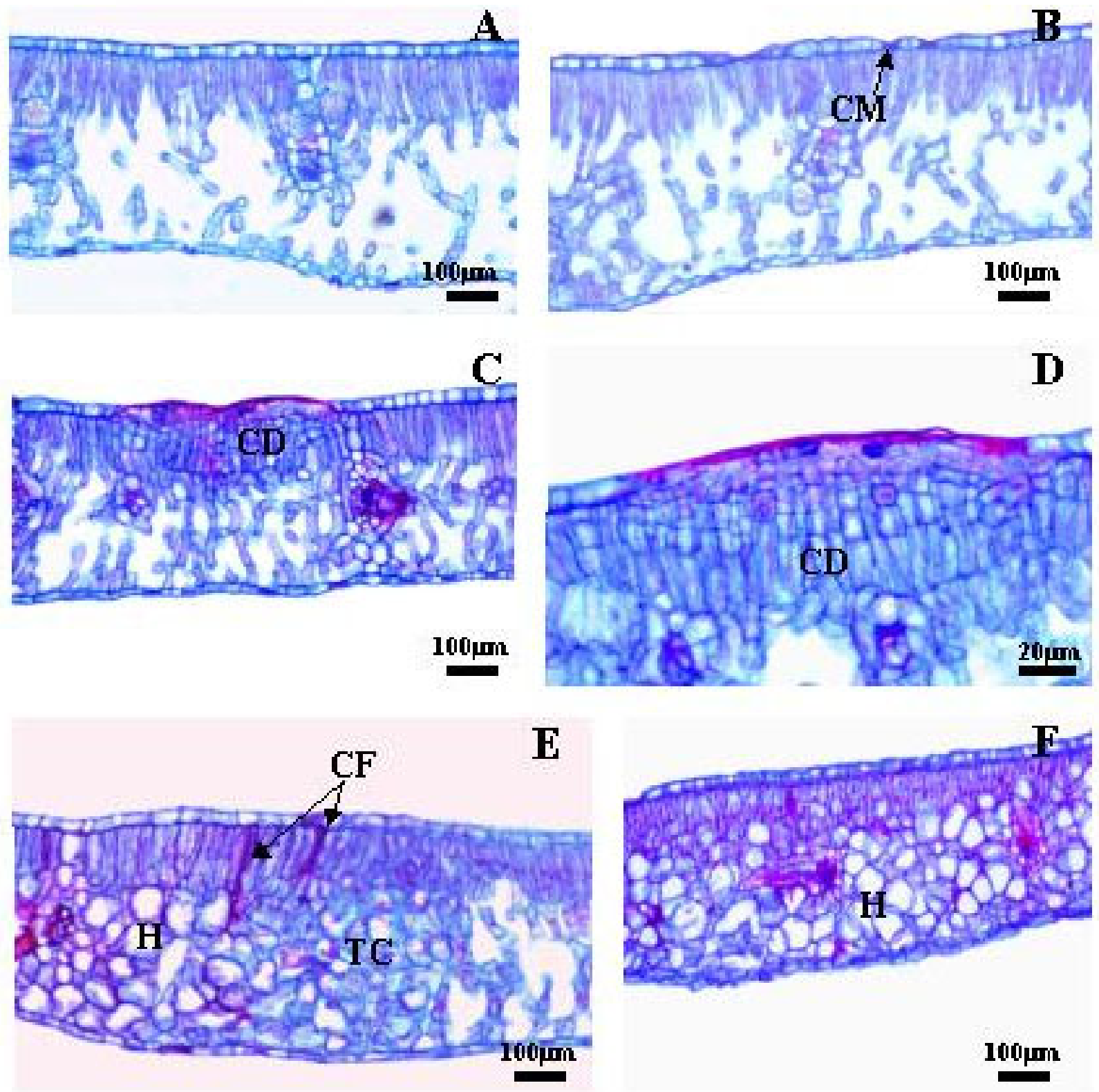

$100 \mu \mathrm{m}$

Figura 4 - Efeito de subdoses de glyphosate na anatomia foliar de Eucalyptus urograndis visto em cortes histológicos. A = testemunha; $\mathrm{B}=86,4 \mathrm{~g}$ e.a. ha ${ }^{-1}$ de glyphosate; $\mathrm{C}$ a $\mathrm{F}=\geq 172,6 \mathrm{~g}$ e.a. ha ${ }^{-1}$ de glyphosate; $\mathrm{CD}=$ células em divisão; $\mathrm{CM}=$ células mortas; $\mathrm{CF}=$ compostos fenólicos; $\mathrm{H}=$ hiperplasia celular; $\mathrm{TC}=$ tecido de cicatrização. 
com 172,8 e 345,6 g e.a. ha ${ }^{-1}$ de glyphosate e no material diafanizado de plantas tratadas com 345,6 g e.a. ha ${ }^{-1}$ (Figura 4C e D e 5F). Vários são os efeitos secundários deste herbicida na planta, entre eles o aumento dos níveis endógenos de etileno (Cole, 1982) e o decréscimo no movimento do AIA em trabalho realizado com coleóptilos de milho (Baur, 1979). Dessa forma, o desbalanço hormonal pode ser a possivel causa das divisões celulares freqüentes nos tecidos expostos às maiores doses do herbicida.
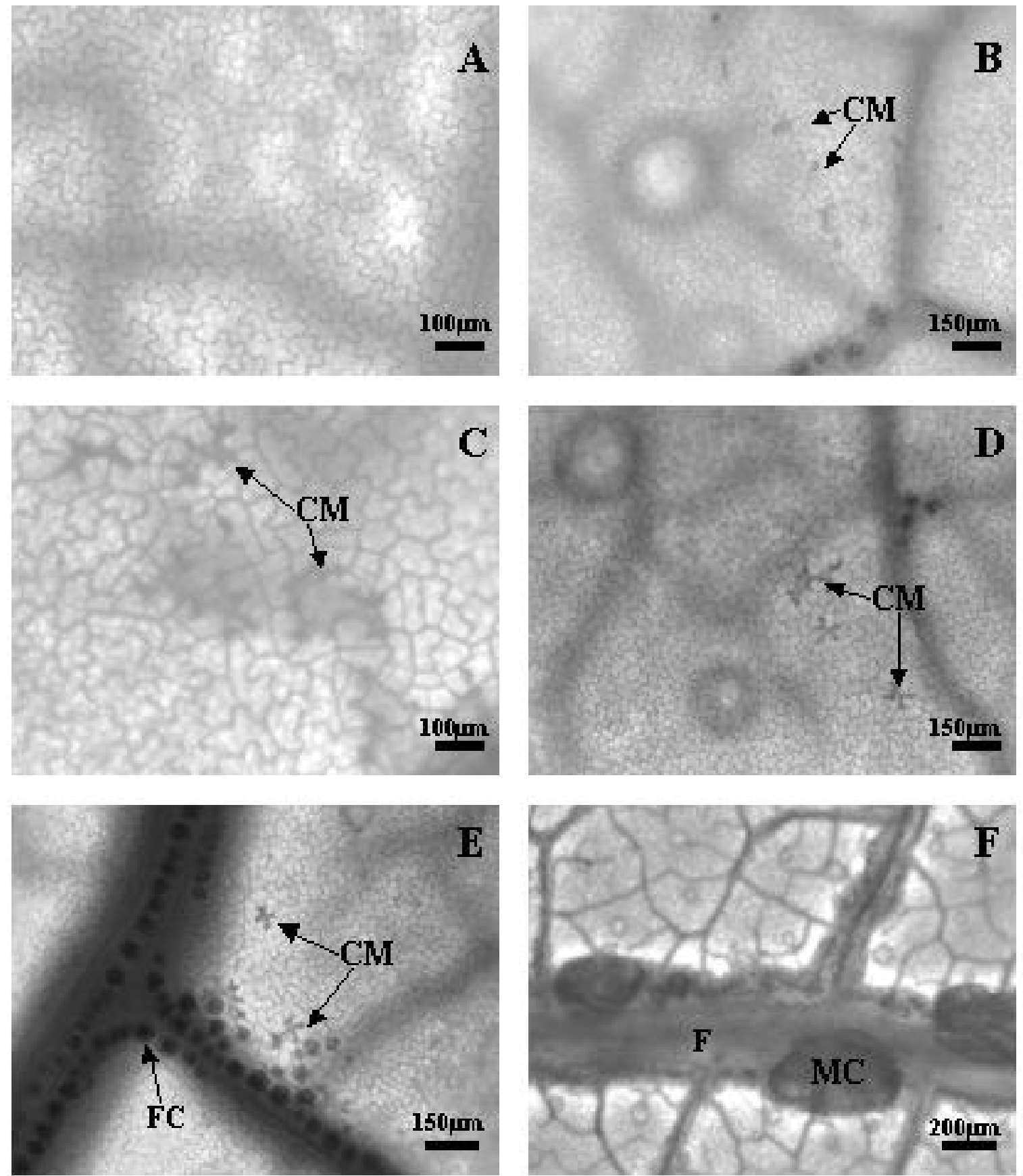

Figura 5 - Efeito de subdoses de glyphosate na anatomia foliar de Eucalyptus urograndis visto em material diafanizado. $\mathrm{A}=$ testemunha; $\mathrm{B}$ a $\mathrm{F}=$ doses $\geq 86,4 \mathrm{~g}$ e. $\mathrm{a} . \mathrm{ha}^{-1}$ de glyphosate; $\mathrm{CM}=$ células mortas da epiderme adaxial; $\mathrm{F}=$ feixe vascular; $\mathrm{FC}=$ feixe vascular com drusas; $\mathrm{MC}=$ massa de células. 
Tabela 2 - Valores médios ( \pm desvio-padrão) da espessura do limbo e de tecidos foliares ( $\mu$ m) e da área percentual de cada tecido foliar de plantas de eucalipto submetidas às doses de $0 ; 43,2 ; 86,4 ; 172,8$; e 345,6 $\mathrm{g} \mathrm{e.a}^{\text {. ha }}{ }^{-1}$ do glyphosate, aos $7 \mathrm{e}$ 15 dias após aplicação (DAA)

\begin{tabular}{|c|c|c|c|c|c|c|}
\hline & \multirow{2}{*}{ Tecido } & \multicolumn{5}{|c|}{ Dose de glyphosate (g e.a. ha $\left.{ }^{-1}\right)$} \\
\hline & & 0 & 43,2 & 86,4 & 172,6 & 345,2 \\
\hline \multirow{9}{*}{$\underset{⿱}{\stackrel{5}{0}}$} & Limbo $(\mu \mathrm{m})$ & $277,58 \mathrm{ab}$ & $265,23 \mathrm{~b}$ & $276,09 \mathrm{ab}$ & $277,57 \mathrm{ab}$ & $318,91 \mathrm{a}$ \\
\hline & $\mathrm{PPA}(\mu \mathrm{m})$ & $87,43 \mathrm{~b}$ & $82,25 \mathrm{~b}$ & $90,59 \mathrm{~b}$ & $83,95 \mathrm{~b}$ & $114,92 \mathrm{a}$ \\
\hline & $\operatorname{PLA}(\mu \mathrm{m})$ & $158,50 \mathrm{a}$ & $139,12 \mathrm{a}$ & $158,38 \mathrm{a}$ & $161,33 \mathrm{a}$ & $172,63 \mathrm{a}$ \\
\hline & $\operatorname{EAD}(\mu \mathrm{m})$ & $16,23 \mathrm{a}$ & $13,53 \mathrm{a}$ & $13,76 \mathrm{a}$ & $14,72 \mathrm{a}$ & $14,74 \mathrm{a}$ \\
\hline & $\mathrm{EAB}(\mu \mathrm{m})$ & $14,23 \mathrm{a}$ & $13,54 \mathrm{a}$ & $13,66 \mathrm{a}$ & $14,83 \mathrm{a}$ & $14,14 \mathrm{a}$ \\
\hline & $\% \mathrm{PPA}$ & $25,04 \pm 3,11$ & $25,81 \pm 2,74$ & $25,12 \pm 3,15$ & $24,01 \pm 7,24$ & $28,26 \pm 7,01$ \\
\hline & \% PLA & $61,15 \pm 3,53$ & $58,96 \pm 3,96$ & $61,39 \pm 3,18$ & $61,45 \pm 8,01$ & $57,86 \pm 12,1$ \\
\hline & $\% \mathrm{EAD}$ & $7,33 \pm 0,88$ & $8,50 \pm 1,27$ & $7,42 \pm 1,72$ & $7,19 \pm 1,17$ & $10,13 \pm 0,89$ \\
\hline & $\%$ EAB & $6,49 \pm 0,91$ & $6,70 \pm 0,59$ & $5,85 \pm 1,08$ & $6,42 \pm 1,54$ & $4,14 \pm 1,11$ \\
\hline \multirow{9}{*}{ 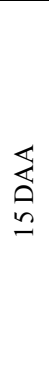 } & $\operatorname{Limbo}(\mu \mathrm{m})$ & $272,91 \mathrm{c}$ & $278,77 \mathrm{bc}$ & $275,90 \mathrm{bc}$ & $333,20 \mathrm{ab}$ & $349,77 \mathrm{a}$ \\
\hline & $\mathrm{PPA}(\mu \mathrm{m})$ & $87,90 \mathrm{bc}$ & $80,21 \mathrm{c}$ & $82,02 \mathrm{bc}$ & $102,90 \mathrm{ab}$ & $125,12 \mathrm{a}$ \\
\hline & $\operatorname{PLA}(\mu \mathrm{m})$ & $151,86 \mathrm{~b}$ & $168,28 \mathrm{ab}$ & $170,56 \mathrm{ab}$ & $196,55 \mathrm{ab}$ & $201,42 a$ \\
\hline & $\operatorname{EAD}(\mu \mathrm{m})$ & $15,42 \mathrm{~b}$ & $14,93 \mathrm{~b}$ & $14,36 \mathrm{~b}$ & $15,24 \mathrm{~b}$ & $18,52 \mathrm{a}$ \\
\hline & $\mathrm{EAB}(\mu \mathrm{m})$ & $13,53 \mathrm{a}$ & $12,79 a$ & $11,29 \mathrm{a}$ & $11,67 \mathrm{a}$ & $13,01 \mathrm{a}$ \\
\hline & $\%$ PPA & $15,02 \pm 4,90$ & $14,21 \pm 3,95$ & $17,14 \pm 1,17$ & $16,51 \pm 4,65$ & $20,10 \pm 7,51$ \\
\hline & \% PLA & $76,46 \pm 6,91$ & $78,53 \pm 6,52$ & $75,08 \pm 9,63$ & $74,66 \pm 17,79$ & $71,26 \pm 7,48$ \\
\hline & $\%$ EAD & $4,67 \pm 1,41$ & $3,62 \pm 1,21$ & $4,01 \pm 0,80$ & $4,20 \pm 2,11$ & $4,54 \pm 1,12$ \\
\hline & $\% \mathrm{EAB}$ & $3,85 \pm 0,67$ & $3,64 \pm 0,55$ & $3,78 \pm 0,38$ & $4,63 \pm 1,00$ & $4,10 \pm 1,55$ \\
\hline
\end{tabular}

Médias seguidas de mesma letra na linha não diferem entre si pelo teste de Tukey a $5 \%$ PPA $=$ parênquima paliçádico, PLA $=$ parênquima lacunoso, $\mathrm{EAD}=$ epiderme adaxial e $\mathrm{EAB}=$ epiderme abaxial.

As médias referentes à espessura do PPA, PLA, EAD e EAB e seus respectivos testes de médias e desvio-padrão encontram-se dispostos na Tabela 2. As espessuras do limbo foliar e parênquima paliçádico (PPA) variaram entre as diferentes subdoses testadas nas avaliações dos 7 e 15 DAA. Para o parênquima lacunoso (PLA) e a epiderme da face adaxial (EAD) foram observadas mudanças somente aos 15 DAA $(p<0,01)$, com destaque para maior dose. Não houve variação em espessura para epiderme da face abaxial $(\mathrm{EAB})(\mathrm{p}>0,05)$ nos períodos avaliados.

Aos 7 DAA verificou-se aumento na espessura do limbo e do PPA submetidos à dose de $345,6 \mathrm{~g} \mathrm{ha}^{-1}$ de glyphosate, ao passo que o PLA e a EAD demonstraram acréscimo na espessura somente aos 15 DAA, sob o mesmo tratamento. O aumento da espessura do limbo e do PPA também foi observado em plantas tratadas com 172,8 $\mathrm{g} \mathrm{ha}^{-1}$ de glyphosate aos 15 DAA (Tabela 2). Os dados relativos à proporção de tecidos foliares mostram uma tendência de aumento do PPA com o aumento das doses aplicadas aos 7 e 15 DAA. O aumento na espessura e na área proporcional do PPA pode ser uma resposta das plantas para compensar a perda de área fotossintética perdida pela senescência foliar e pelas necroses, causadas pela ação do glyphosate. Abu-Irmaileh et al. (1979) relataram o aumento na produção de celulases e etileno em plantas de feijão tratadas com glyphosate. O aumento dessas enzimas nos tecidos foliares do eucalipto pode afrouxar a estrutura da parede celular das células do mesofilo, possibilitando-lhe a expansão destas células. Entretanto, o etileno inibe a expansão celular (Burg, 1973), sendo necessários estudos bioquímicos complementares dos efeitos do glyphosate em eucalipto, visando elucidar os processos envolvidos.

\section{LITERATURA CITADA}

ABU-IRMAILEH, B. F.; JORDAN, L. S.; KUMAMOTO, J. Enhancement of $\mathrm{CO}_{2}$ and ethylene producion and cellulase activity by glyphosate in Phaseolus vulgaris. Weed Sci., v. 27, n. 1, p. 103-106, 1979.

Planta Daninha, Viçosa-MG, v. 23, n. 1, p. 133-142, 2005 
AHRENS, W. H. Glyphosate. In: AHRENS, W. H. (Ed.) Herbicide handbook. Champaign: Weed Science Society of America, 1994. p. 149-152.

BAUR, J. R. Effect of glyphosate on auxin transport in corn and cotton. Plant Physiol., v. 63, p. 882-886, 1979.

BODE, L. E. Downwind drift deposits by ground applications. In: PESTICIDE DRIFT MANAGEMENT SYMPOSIUM, 1984, Brookings. Proceedings... Brookings: South Dakota State University, 1984. p. 50.

BURG, S. P. Ethylene in plant growth. Proc. Nat. Acad. Sci., v. 70, p. 591-597, 1973.

CAMPBELL, W. F.; EVANS, J. O.; REED, F. C. Effect of glyphosate on chloroplast ultrastructure of quack grass mesophyll cell. Weed Sci., v. 24, p. 22-25, 1976.

COLE, D. J.; CASELEY, J. C.; DODGE, A. D. Influence of glyphosate on selected plant process. Weed Res., v. 23, p. 173-183, 1983.

DANTAS, F. W. F.; SOUZA, A. J.; CIERO, A. D. Controle da rebrota de eucalipto em área de reflorestamento. In: SEMINÁRIO NACIONAL SOBRE HERBICIDAS E TECNOLOGIA DE APLICAÇÃO EM FLORESTAS, 2001, Viçosa-MG. Anais... Viçosa-MG: SBS/SIF, 2001. p. 29-44.

FRANS, R. E. Measuring plant responses. In: WILKINSON, R. E. (Ed.) Research methods in weed science. (S.1.): Southern Weed Science Society, 1972. p. 28-41.

GERLACH, D. Botanische mikrotechnik. Stuttgard: Georg Thieme Verlag. 1984. 311 p.

GELMINI, G. A. Herbicidas: indicações básicas. Campinas: Fundação Cargil, 1988. 334 p.

HEMPHILL JR., D. D.; MONTGOMERY, M. L. Response of vegetable crops to sub lethal application of 2,4-D. Weed Sci., v. 29, n. 6, p. 632-635, 1981.

JOHANSEN, D. A. Plant microtechique. New York: McGraw-Hill Book, 1940. 523 p.
LÉVESQUE, C. A.; RAHE, J. E. Herbicide interaction with fungal root pathogens, with special reference to glyphosate. Ann. Rev. Phytopathol., v. 30, p. 579-602, 1992.

MAGALHÃES, P. C. et al. Efeito de doses reduzidas de glyphosate e paraquat simulando deriva na cultura do milho. Planta Daninha, v. 19, n. 2, p. 247-253, 2001 a.

MAGALHÃES, P. C. et al. Efeito de doses reduzidas de glyphosate e paraquat simulando deriva na cultura do sorgo. Planta Daninha, v. 19, n. 2, p. 255-262, 2001 b.

MALIK, J.; BARRY, G.; KISHORE, G. The herbicide glyphosate. Biofactores, v. 2, p. 17-25, 1989.

RIBEIRO, G. T. Uso de herbicidas pré-emergentes em Eucalyptus sp. na região do cerrado. In: SEMINÁRIO TÉCNICO SOBRE PLANTAS DANINHAS E O USO DE HERBICIDAS EM REFLORESTAMENTO, 1988, Rio de Janeiro. Anais... Rio de Janeiro: SBS/ABRACAVE/SIF, 1988. (paginação irregular)

RIZZARDI, M. A. et al. Ação dos herbicidas sobre o mecanismo de defesa das plantas aos patógenos. Ci. Rural, v. 33, n. 5, p. 957-965, 2003.

RODRIGUES, B. N.; ALMEIDA, F. S. Guia de herbicidas. (Eds): Londrina: 1998. 331 p.

SASS, J. E. Botanical microtechnique. 3.ed. Iowa: State Press, 1951. 228 p.

SOCIEDADE BRASILEIRA DE SILVICULTURA - SBS. Dados estatísticos sobre a produção nacional de eucalipto. Sociedade Brasileira de Silvicultura. Disponível em: <http://www.sbs.org.br/secure/estatisticas.htm>. Acesso em: 25 maio 2004.

TOLEDO, R. E. B. et al. Faixas de controle de plantas daninhas e seus reflexos no crescimento de plantas de eucalipto. Sci. For., v. 64, p. 78-92, 2003.

TUFFI SANTOS, L. D. et al. Efeito do glyphosate sobre a morfoanatomia das folhas e do caule de Commelina diffusa e C. benghalensis. Planta Daninha, v. 22, n. 1, p. 101-107, 2004.

YATES, W. E.; AKESSON, N. B.; BAYER, D. E. Drift of glyphosate sprays applied with aerial and ground equipment. Weed Sci., v. 26, n. 6, p. 597-604, 1978. 